\title{
MEDICAL SURVEILLANCE OF THE WORK OF THE CLINIC-BASED MIDWIFE
}

\author{
J. V. Larsen, M.B. ChB., M.R.C.O.G. \\ Department of Obstetrics and Gynaecology, King Edward VIII Hospital
}

\section{OPSOMMING}

'n Moontlike struktuur vir die doeltreffende toesig oor kliniese vroedvroue in 'n omvattende gesondheidsprogram word aangebied.

Daar word vyf toesigmetodes beskryf wat elkeen 'n ander mikpunt het.

\section{INTRODUCTION}

$\mathbf{T}$ HE Comprehensive Health Programme of the South African Department of Health is based upon the concept of a base hospital linked with peripheral clinics staffed by nursing sisters. Supervision and training of such nurses is normally carried out by medical staff visiting from the base hospital. In the case of midwifery, the methods of medical supervision of the staff must be different from those employed in a hospital situation.

It is important to the success of such a programme at the clinic level that medical supervision be highly effective. This is because existing clinics are frequently staffed by midwives who qualified some time ago, and who are out of touch with recent advances in obstetrics. In addition, if the clinic service is to be acceptable to the community, it must aim at a zero Perinatal Mortality Rate. Only then is the community likely to make full use of its obstetric services, thereby keeping all normal deliveries out of the base hospital.

Unfortunately most doctors are trained to work in a hospital environment ${ }^{\prime}$, and they thus find difficulty in 
defining their role in the supervision of the clinic midwife. If doctors are to adapt easily to this situation, they must be introduced to the concept of the Comprehensive Health Programme as medical students.

\section{BASIC PRINCIPLES}

Certain basic principles must be established before details are considered.

1. The primary health care unit in this structure is the midwife, not the medical of ficer. It is not valid use of the doctor's time, nor does it increase patient confidence in the midwife's ability, for the doctor to see all the patients at a peripheral antenatal clinic.

2. The doctor's task must be to provide training for, and supervision of, the midwife, so that she can successfully detect the high risk patient, in the antenatal, intrapartum, or postpartum periods. Such patients should then be transferred timeously to the base hospital, or referred to the doctor on one of his regular weekly or fortnightly visits. She should be able to manage patients with normal pregnancies without his assistance.

3. Monitoring the midwife's work under these circumstances is only possible if a high standard of clinical notekeeping is maintained, both in the clinic and in the base hospital. This implies that each patient must have a maternity case record which will form a satisfactory record of her whole pregnancy, including her confinement and puerperium. Such a record should accompany her to the hospital if she is referred there for delivery. It must also be adequately completed and returned to the clinic when she is discharged. This is the only way of ensuring good communications, and thus enabling a high standard of patient care in a community obstetric programme. Good communications can only be achieved if hospital staff recognise the clinic as an integral part of the obstetric service, and they frequently need considerable re-education in this regard. The supervising doctor must be prepared to discuss inadequately completed charts with the medical and nursing staff concerned. He should also be prepared to arrange clinic visits for hospital staff, and even to organise the rotation of hospital nursing staff through the clinics.

4. During his clinic visits, the doctor should also be prepared to pay attention to incidental problems such as equipment, transport, and water supplies.

\section{METHODS OF SURVEILLANCE Referrals}

The records of all patients referred from each clinic to the hospital should be critically reviewed at fortnightly or monthly intervals. Such a review should take place against a background of a clear management protocol for each condition encountered in that obstetric population. The objects of this examination of patients' records should be to:

(a) test and modify where necessary, management protocols,

(b) detect inadequate management of patients, whether or not this resulted in morbidity or perinatal mortality,

(c) detect unnecessary transfers and referrals, and

(d) detect patients who have been exceptionally well managed.

Any findings should be discussed with the whole clinic staff when the charts are returned to the clinic. Changes in management protocols can be worked out, the reasons for failure in management identified and corrected, and the necessary encouragement and praise shared when tasks have been well done. The midwives' participation in decision-making in this way improves understanding and the level of trust between clinic and base hospital staff. It also incidentally usually means that better decisions are made by the medical staff when improving management protocols.

A similar review should be made of patients referred at the clinic for the doctor's assessment, each patient's problem thus forming a teaching opportunity.

\section{Random Patient Review}

With the clinic midwives' knowledge, antenatal patients or patients in labour at the clinic, who have been previously assessed by her, are reassessed by the supervising doctor. This method enables him to monitor the accuracy of her observations, from screening the heart and lungs to pelvic assessment, and will help him to determine the details and direction of further practical training in technique which the midwife may require. It also incidentally allows assessment of the standards of aseptic technique pertaining in the clinic, and whether the equipment is adequate in quality and quantity.

\section{Clinic Antenatal Record Review}

Time can be profitably spent in examining all the antenatal records of patients attending the clinic. This is especially so if a method of problem-orientated antenatal notekeeping is employed. A suitable method is described elsewhere ${ }^{2}$. This method of notekeeping enables the medical officer to see immediately whether a high risk factor has been detected, and whether appropriate action has been taken. Where such factors have been missed, or the correct action has not been indicated, he can write it into the chart, at the same time discussing the patient with the clinic staff, thus ensuring that the patient's problem is correctly dealt with at her next visit.

\section{Clinic Perinatal Mortality and Morbidity Meetings}

These should be organised on a regular basis, the number of meetings per year depending upon such factors as the number of patients delivered at the clinic. Where numbers are small, a meeting for staff from a group of clinics may be valuable. The senior nursing staff at each clinic should be encouraged to do the background work, gathering the case records of all stillbirths, neonatal deaths, and babies with low APGAR scores, as well as any maternal deaths. This review should include all patients transferred to the hospital during the period in question, as well as those delivered in the clinic. As far as is possible, learning from these patients should take place by peer review, the midwives themselves being encouraged to identify the factors which lead to mortality or morbidity, and to suggest where treatment could have been improved. This affords the doctor the opportunity of observing how much of his instruction has been understood, and whether it is being applied in problem solving. 


\section{Regular Formal Inspections}

These should be carried out with the senior nursing officer of the health ward. Special attention should be given during such inspections to the standard of aseptic technique, the maintenance of equipment, the organizational aspects of antenatal, intrapartum and postnatal care, and the adequacy of communications and transport arrangements. They should not simply involve the inspection of general clinic cleanliness and drug records, but should be a forum for discussion between the medical and nursing authorities and the clinic staff, directed at achieving a better standard of service and improved working conditions.

\section{DISCUSSION}

Five methods of surveillance of the clinic midwife's work have been detailed. Each has slightly different aims. Use of all five will result in adequate monitoring of the following areas of her work:

(1) The indications she employs for referring patients, and her management of patients at risk.

(2) The standard of her clinical observations and technical ability.

(3) The unrecognised problems which pass through her antenatal clinic.

(4) Her ability to recognise and learn from her mistakes.

(5) The nursing and organisational standards of the service she offers.

It is the author's experience that the use of all five methods can result in the development of a service of considerable excellence.

My thanks are due to Dr. I. Dhupelia and Dr. S. Ross for some ideas which have been incorporated in this paper, and to Professor R. H. Philpott for his criticism and assistance in its preparation.

REFERENCES:

1. Wagstaff, L.A. (1978): South African Medical Journal 53:805

2. Larsen J.V.: Problem-orientaled antenatal note keeping: Curationis, Vol. 1. No. 3, December 1979: Publishers: S.A. Nursing Association. 